\title{
The Impact of Infrastructure on Tourism: The Case of Sri Lanka
}

\author{
A. M. M. Mustafa ${ }^{1}$ \\ ${ }^{1}$ Faculty of Management and Commerce, South Eastern University of Sri Lanka, Sri Lanka \\ Correspondence: A. M. M. Mustafa, Faculty of Management and Commerce, South Eastern University of Sri \\ Lanka, Oluvil, Sri Lanka. E-mail: amustafa@seu.ac.lk
}

Received: May 28, 2019 Accepted: June 17, $2019 \quad$ Online Published: June 30, 2019

doi:10.5539/ass.v15n7p174

URL: https://doi.org/10.5539/ass.v15n7p174

\begin{abstract}
This study examines the impact of infrastructure on tourism development in Sri Lanka with greater emphasis on road network. The time period used in this study are ranging from year 2005 to year 2017. The annual time series data are analyzed by using statistical package, E-Views 10 after the preliminary calculations by using Microsoft Excel. The unit root of the variables is tested by ADF test to test the stationarity of the time series data used in the model of this study. Co-integration is tested with the use of Engle-Granger. The relationship of causality between the variables is found by test of Granger Causality. The results show that infrastructure has significant short run as well long run positive impact on tourism. Two-way causal relationship is found between tourism sector and infrastructure. Further, this study recommends that the government should play its role in improving the infrastructure facilities to increase tourist's arrival in Sri Lanka.
\end{abstract}

Keywords: tourism, infrastructure, road transport

\section{Introduction}

The improvement in infrastructural facilities in the developed or developing countries all over the world leads to the various impacts in the countries concerned. In developing countries, the infrastructural facility is one of the significant attractive pillars for the development of tourism sector. The contribution of the infrastructural facilities to the economic development of the countries leads to improve productivity and provide amenities that boost the living standards and condition of the people. As a result, the infrastructural facilities such the road network, availability of electricity, telecommunication, and water supply are generally perceived as the necessary determinants for the economic growth and development. A potential role of the infrastructural facilities to attract a greater number of tourists to the respective countries is found by a number of researches (Reynolds et al., 2004; Yol \& Teng, 2009). Infrastructural facility is a part of a structure which is defined as an economic or material base of a community. As a result, the infrastructural structure represents the essential structural base that motivates the better performance of the essential services of the respective countries or cities. Accordingly, a better infrastructural system in logistics in transportation can be established by the private and public investments in the countries (Bulbeck, 2005). The organizations need to improve the infrastructural facilities which are compatible to the current needs and wants of the tourists so as to distribute their touristic products and services among other produces all over the world. (Onyeocha et al., 2015). Road network is defined as an exclusive route connecting two or a number of places. The road networks are typically constructed in different ways so as to enable easy travelling. In history, those roads are constructed simply without any proper construction method. The streets are the road which may be passing through the cities or villages in a countries (Groth, 2000). The term transportation infrastructure as defined by O.U Alex- (Onyeocha et al., 2015) denotes to fixed installation such as buildings that are essential for transport and includes among others roads, airways, waterways, and terminals such as airports, railway stations, bus stations, warehouses, refueling depots. The destinations and the places of origins of the tourists are liked by the transportation system. Absence of the transportation system does not add any of value to the potential resources which are compatible to the touristic attractions. Planning to promote tourism sector in a place is void without the transportation system in the place. This system distributes an access throughout the touristic destinations or attractions in the respective countries or places. The entire system of transpiration is composed of modes and means of transport. A country is mostly attracted by the tourists by the presence of alternative transpirations facilities. There are several development projects being implemented in Sri Lanka to improve the tourism sector throughout the country during the past decades. The post war scenario recorded a sudden drastic increase in the arrivals of tourists in Sri Lanka. In Sri 
Lanka, there are 39 touristic attractions found island wide. The arrivals of tourists are 407511 and 447890 in year 1994 and year 2009 respectively. Tourism sector has reached to a new landmark of 1,274,593 tourists' arrivals in year 2013, exceeding high records in the history that is recorded as 26.7 percent increase over the arrivals in year 2012 as 100,560 . In year 2015, the arrival of tourist is 1788390 and in 2017, the arrivals of tourist are 2116407 (Tourism Development Authority, 2018). The development is in progress in the sectors of Sri Lanka after the cease fire in Sri Lanka. The cease fire paved the way for a flourishing future for the Sri Lankans and a thriving environment in connection with the economy and business. 05-year tourism strategic plan targets 2.5 million tourists to be attracted to Sri Lanka in the next five years (Ministry of Economic Development, 2011-2016).

\section{Literature review}

Many articles in the literature have highlighted the importance on Infrastructure as one of the determinants of Tourism inflow to a country. Fareed et al. (2016) did a research on the effect of terrorism and infrastructure on tourism industry: A case of Pakistan. Collected time series data for 1989 to 2011 and linear regression was applied to find the results. The article finds that terrorism significantly influences tourism in adverse manner and infrastructure positively influences tourism industry in Pakistan. The study of Hultsman et al. (1999) taking Turkey as a destination country explained infrastructure as important factor attracting tourists. He takes sum of roads, services and communication facilities. A study by Gunn et al. (2002) found infrastructure to be an important factor for the recognition of Thailand as a favorable country for tourism. Found government infrastructure to be an important determinant for South African Tourism industry. Yoon et al. (2005) also recognized the importance of infrastructure for tourism development in 51 islands. Alegre et al. (2006) used panel data to study factors responsible for tourism inflow in Africa and found infrastructure, political stability and safety of individuals as strong determinants. There is no research carried out in the field in Sri Lankan context, even though there are a number of different studies carried out all over the world in this context, the findings and conclusions of those studies are different about the factors which are determining the tourism sector and infrastructural facilities. Thus, that isn't mostly fit to outline in Sri Lanka. At this background, this study examines the connection between infrastructural facilities and the sector of tourism in Sri Lanka econometric and descriptive basis of the variables found in the literatures above reviewed in this context.

\section{Objective of the Study}

The main objective of this study is to analyze empirically the effect of infrastructure on tourism industrial sectors of Sri Lanka. The specific objectives of the research are:

- To examine visual inspection for the relationship between the variables.

- To examine the time series properties of variables used in this study.

- $\quad$ To test long -run association between the variables

- To examine the short-run dynamic of the system.

- To examine Granger Causality test to identify the directional relationship.

- To examine the residual Distribution and Diagnostic tests based on the model.

\section{Methodology}

In this study, the statistical tools used in this study to analyze the data are Multiple Regression Model, Correlation analysis, Granger Causality, Unit root, and Co-integration. Under Multiple Regression Model, OLS method is considered to estimate the value of parameters of the variables. The causal relationship between the dependent variable and the independent variables is tested by Granger Causality. The stationarity of all the variables is tested by ADF. The long run relationship between tourism sector and the infrastructural facilities is examined by the test of Co-integration. E-views econometric software 10is used for the data analysis. The following model (1), based on Fareed et al. (2016), is formulated to find the effect of the infrastructural facilities on the tourism sector of Sri Lanka. Thus, the following mathematical function is constructed in order to find the relationship between the contribution of infrastructural facilities and the tourism sector in Sri Lanka. Accordingly, the multiple regression model is defined as follows:

$$
T A_{t}=\beta_{0}+\beta_{1} R K_{t}+\beta_{2} S R_{t}+\varepsilon
$$

Where TR is tourism arrival, RK is Road Kilometers; SR is Sri Lanka Railway Kilometer, $\mathcal{E}$ is the error term and $\beta_{0}, \beta_{1}$ and $\beta_{2}$, are parameters. 


\section{Results and Discussion}

Macroeconomic phenomena of an economy are considerably influenced by the tourism sector. In this part, the parametric and non-parametric techniques are used to examine and evaluate the relationship and the impacts of infrastructural facilities and the tourism sector in Sri Lanka. The statistical tools used to analyze the data under nonparametric approach are listed as Kernal Fit, Nearest Neighbor fit, and Confidence Ellipse. In contrast, under parametric techniques, the tools used in this study are the analysis of Co-integration, Error Correction Mechanism, and Granger Causality.
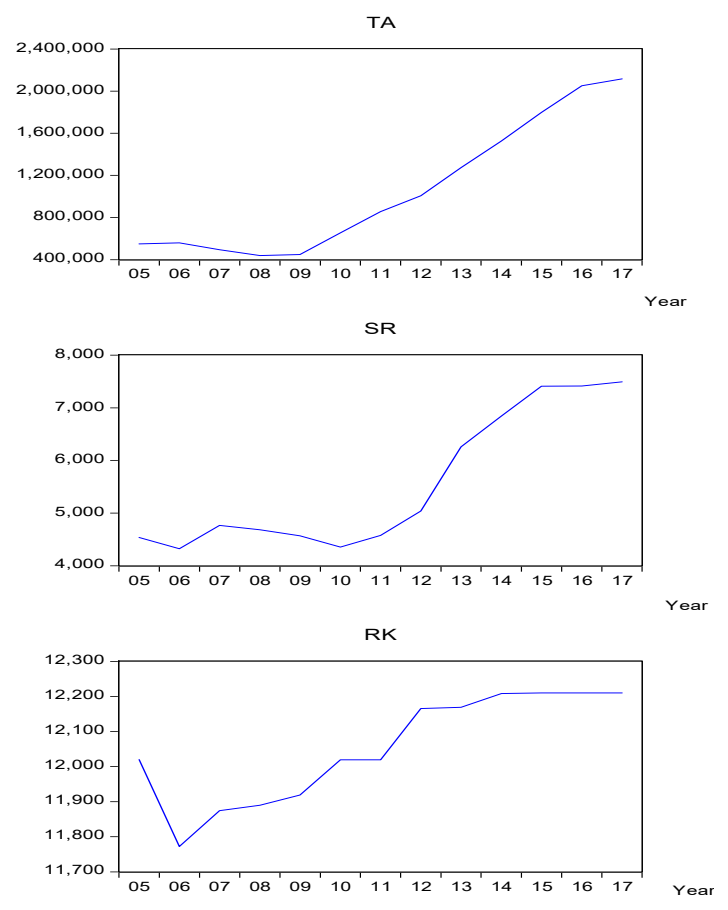

(Source: Central Bank of Sri Lanka. 2018).

Figure 1. The trend of variables in the particular period (2005-2017)

The above Figure 1, Sri Lanka behavior of share of TA, SR and RK year from 2005 to 2017.

Visual Inspection for the relationship between Variables
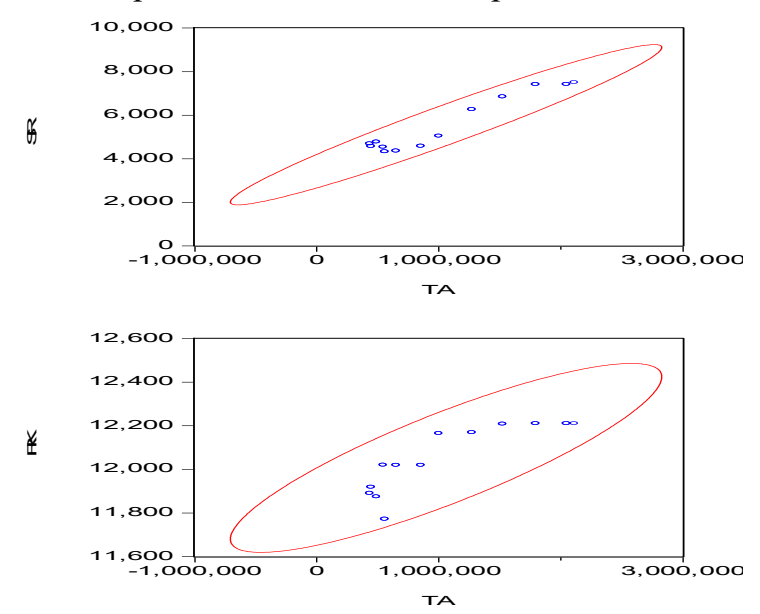

Figure 2. Confidence ellipse (TA\&SR, TA\&RK)

The above Figure 2 which is depicting the graphical representation of the variables used in this study is especially significant so as to find the trend and the principal connection between the variables such as SR and TA. A positive relationship is shown by the graph of Confidence Ellipse between the variables such as SR and TA. In addition, it is found that the variables such as SR and TA are correlated. The Confidence ellipse graph 
shows that the direct relationship between RK and TA. Further, it shows the series of RK and TA are having the correlational relationship.
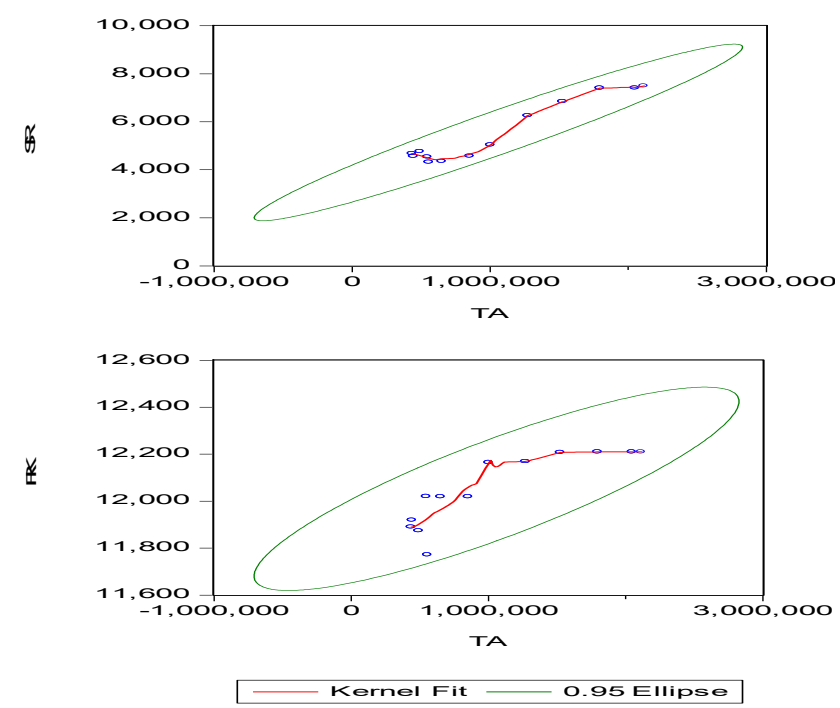

Figure 3. Kernel Fit and Confidence ellipse (TA\&RK, TA \& SR)

The pictorial presentation of the variables shown in Figure 3 is very helpful to find the movement and fundamental associationship between the variables such as TA and RK used in this study. Confidence Ellipse, Kernel Fit, and the diagrammatic explanation demonstrate strong positive relationship between the variables such as TA and RK. In addition, there is a high correlation between the variables such as TA and RK.

A strong direct relationship is found between TA and SR by using the diagrammatic explanation of Confidence Ellipse and Kernel Fit. In addition, TA and SR series are highly correlated.
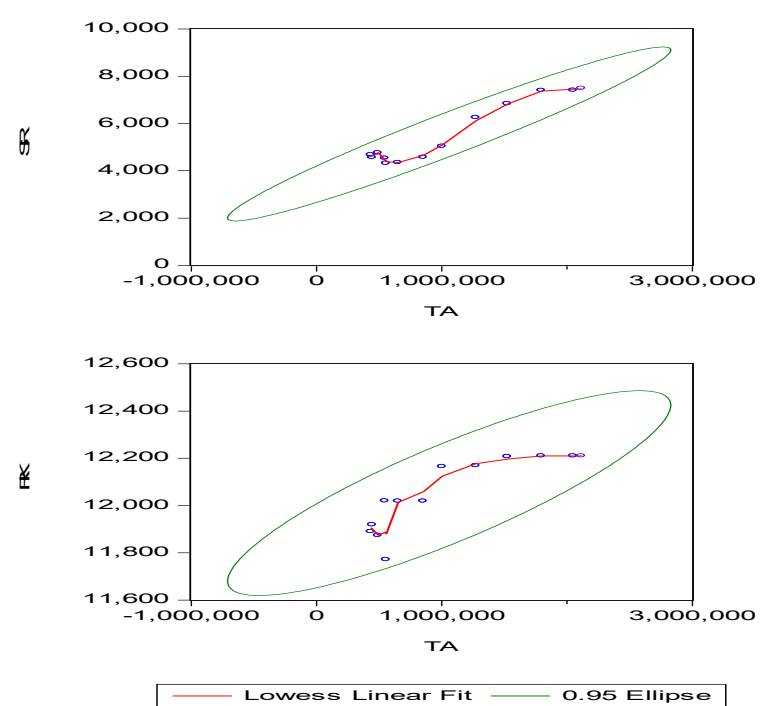

Figure 4. The Nearest Neighbor and Confidence ellipse (TA \&RK, TA \& SR)

Above Figure 4 The diagrammatic explanation of data used in this study is very helpful to find out the movement and fundamental relationship between the variables SR and TA. The Nearest Neighbor and Confidence Ellipse graph indicate that the direct relationship between SR and TA. In addition, it is shown that the series of SR and TA are very much correlated. The Nearest Neighbor and Confidence ellipse portray a direct relationship between RK and TA. In addition, RK and TA series are highly correlated.

\subsection{Unit Root Test (Variables TA, RK, and SR)}

Before testing the long-run relationship of the variables, it is preliminarily essential so as to run a Unit Root test. Accordingly, the preliminary step is to find if the variables used in this study are stationary or non-stationary. If a time series data is non-stationary, the results received from multiple regression model may be misleading the researcher and the readers as well. 
Table 1. Result of Unit Root Test (Variables TA, RK, and SR)

\begin{tabular}{cccc}
\hline Variables & ADF Test & Intercept & Decision \\
& Level & -1.1814 & Non - Stationary I $(1)$ \\
TA & First difference & $-2.2621^{* *}$ & Stationary \\
& Level & -1.2736 & Non - Stationary I(1) \\
RK & First difference & $-8.6319^{*}$ & Stationary \\
& Level & -0.7150 & Non - Stationary I(1) \\
SR & First difference & $-1.6566^{* *}$ & Stationary \\
\hline
\end{tabular}

* Significant at $1 \%$ Level

$* *$ Significant at $5 \%$ Level

The Augmented Dickey-Fuller (ADF) Unit Root is tested on Level and First difference of the variables such as TA, RK, and SR. The above table shows the results of Augmented Dickey Fuller test for the respective variables. On the basis of the results of Augmented Dickey Fuller Test, non-stationarity of the respective variables representing time series data is confirmed at their level form. On the other hand, the stationarity of these variables is confirmed at their First Difference. As a result, the variables such as TA, RK, and SR are integrated of order one, I (1).

\subsection{Unit Root Test for Residual of Co-integration Regression Equation}

Table 2. Unit Root Test for Residual of Co-integration Regression Equation

Null Hypothesis: RESID01 has a unit root

Exogenous: Constant

Lag Length: 2 (Automatic - based on SIC, maxlag=2)

\begin{tabular}{cccc}
\hline & & t-Statistic & Prob.* $^{*}$ \\
\hline Augmented Dickey-Fuller test statistic & & -7.337262 & 0.0002 \\
Test critical values: & $1 \%$ level & -4.297073 & \\
& $5 \%$ level & -3.212696 & \\
& $10 \%$ level & -2.747676 & \\
\hline
\end{tabular}

As per the analysis of Engle- Granger Co-integration, the stationarity of the residual is tested by Unit Root Test (Augmented Dickey-Fuller test). The value of ADF statistics is equal to -7.3372 and the probability value $(p)$ is equal to 0.0002 . As such, based on the above estimated value, the residual of the multiple regression model is stationary. Variables such as TA, RK, and SR, are co-integrated.

Table 3. Co-integration Regression Results for the Model Dependent Variable: TA

\begin{tabular}{cccc}
\hline Variable & Coefficient & $\mathrm{t}$ Value & Probability $(\mathrm{p})$ \\
\hline$\beta_{0}$ (Intercept $)$ & -16514240 & -2.409288 & $0.0393^{* *}$ \\
RK & 1307.788 & 2.190858 & $0.0562^{* *}$ \\
SR & 331.5545 & 4.816678 & $0.0010^{*}$ \\
\hline
\end{tabular}

$\mathrm{R}-\mathrm{Sq}(\mathrm{adj})=94 \%$, Akaike info criterion 26.91966, Schwarz criterion 27.04089,

F-statistic 90.71113, Prob. (F-statistic) 0.0001

*Significant at $1 \%$ Level $\quad * *$ Significant at $5 \%$ Level

On the basis of the output of Co-integration regression shown in the table above, the value of adjusted $R^{2}$ is very high and the appropriateness is confirmed by the values F-statistics, Prob (F-statistic), Akaike info criterion, Schewarz criterion. The entire variation of dependent variable of TA is explained by 94 percent of all the independent variables used in the multiple regression model. Hence, the validity of the statistical appropriateness so as to estimate the relationship between the dependent variable and the independent variables is confirmed. The overall multiple regression model is significant at 1 percent level. The positive signs of all the values of coefficient of all the variables confirm the theoretical basis. In addition, the direct long-run association-ship between the variables such as RK and TA is statistically significant at 5 percent level. The direct long-run association-ship between the variables such as SR and TA is statistically significant at 1percent level.

As per the results of Error Correction Mechanism (ECM) in Table 4, the value of adjustment coefficient of the model is estimated at -0.729 along with Probability value of 0.0392 . Hence, the statistical significance and expected signs of the variables are confirmed. Negative signs of the coefficient denote that there is a downward movement of TA towards the path of equilibrium. It means that $72 \%$ of deviation from long-run equilibrium is 
adjusted each year. Hence, it portrays a downward adjustment of TA towards equilibrium path. On the other hand, short-run effect is statistically significant and the multiplier of impact of the variable, RK is also having statistical significance. In addition, it has the expected sign at $5 \%$ significant level. SR is also having a statistical significance. It is having the positive sign at 10 percent level of significance.

Table 4. Results of Error Correction Model (ECM) Dependent Variable: D(TA)

\begin{tabular}{ccc}
\hline Variable & Coefficient & Probability $(\mathrm{p})$ \\
\hline$\beta_{0}$ (Intercept $)$ & 50903.73 & 0.3405 \\
DRK & 208.5547 & $0.0238^{* *}$ \\
DSR & 0.741006 & $0.0934^{* * *}$ \\
RESID01(-1) & -0.729326 & $0.0392^{* *}$ \\
\hline
\end{tabular}

***Significant at $10 \%$ Level $\quad * *$ Significant at $5 \%$ Level

Table 5. Results of Pairwise Granger Causality Tests

\begin{tabular}{ccccc}
\hline Null Hypothesis & Lag & F-Statistic & P-Value & \multicolumn{2}{c}{ Granger Causality } \\
\hline RK does not Granger Cause TA & 1 & 4.57080 & 0.0698 & Yes \\
TA does not Granger Cause RK & 1 & 5.68802 & 0.0485 & Yes \\
\hline
\end{tabular}

As per the results indicated in Table 5, the causal relationship runs from RK to TA. As per the Test of Granger Causality, RK is statistically (value of $p=0.0698$ ) motivated TA. TA statistically ( $\mathrm{p}$ value $=0.0485$ ) motivated RK. Bi way causal relationship is found from RK to TA and from TA to RK.

Table 6. Results of Pairwise Granger Causality Tests

\begin{tabular}{ccccc}
\hline Null Hypothesis & Lag & F-Statistic & P-Value & Granger Causality \\
\hline SR does not Granger Cause TA & 1 & 0.39277 & 0.0507 & Yes \\
TA does not Granger Cause SR & 1 & 10.0731 & 0.0156 & Yes \\
\hline
\end{tabular}

As per the results listed in Table 6, the causal relationship is running from SR to TA. In accordance with the Tests of Granger Causality, SR is statistically (the value of $p=0.0507)$ motivated TA. TA statistically ( $\mathrm{p}$ value $=$ 0.0156) motivated SR. The two-way causal associationship is revealed for the results from SR to TA and from TA to SR.

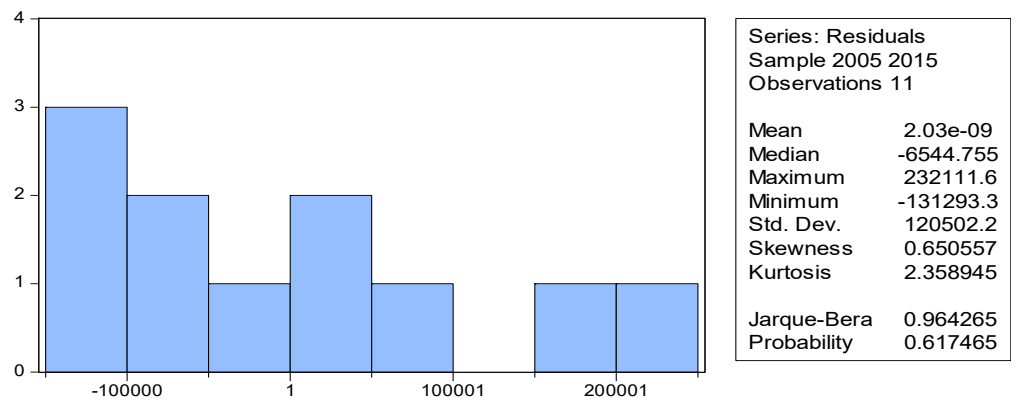

Figure 5. Residual Distribution for the Model

The JB test shows that residual is normality distributed.

Table 7. The results of diagnostic tests based on the model

\begin{tabular}{cccc}
\hline Tests & Statistics & Probability \\
\hline Jarque-Bera (normality test) & & 0.964265 & 0.617465 \\
Heteroskedasticity Test: ARCH & F statistics & 0.036460 & 0.8533 \\
& ObsR-squared & 0.045368 & 0.8313 \\
Bruesh-Godfrey Serial Correlation LM & F statistics & 0.557458 & 0.5997 \\
test: & ObsR-squared & 1.723714 & 0.4224 \\
\hline
\end{tabular}

Based on the results that are shown in the Table 7, the multiple regression model is free from no autocorrelation, 
no non-normality of errors, and no heteroskedasticity. In addition, it is well defined functional form along with stable regression. As a result, the model used in this study is strong. And also, the construction of the multiple regression model represents the sufficient data.

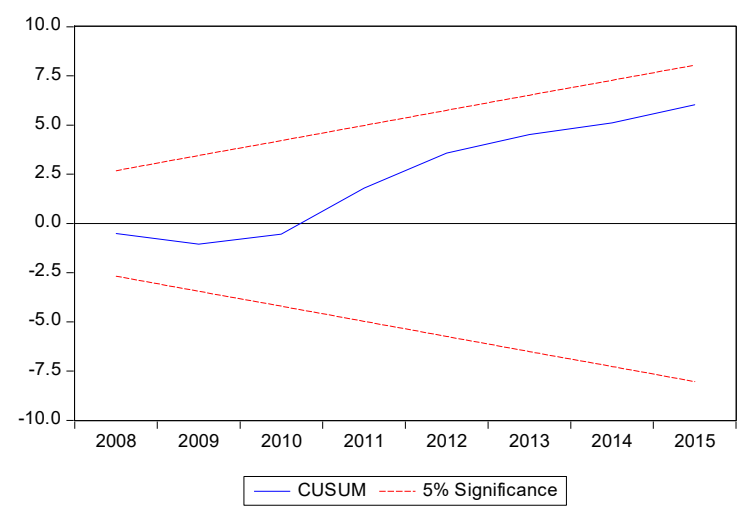

Figure 6. Stability Test (Cusum)

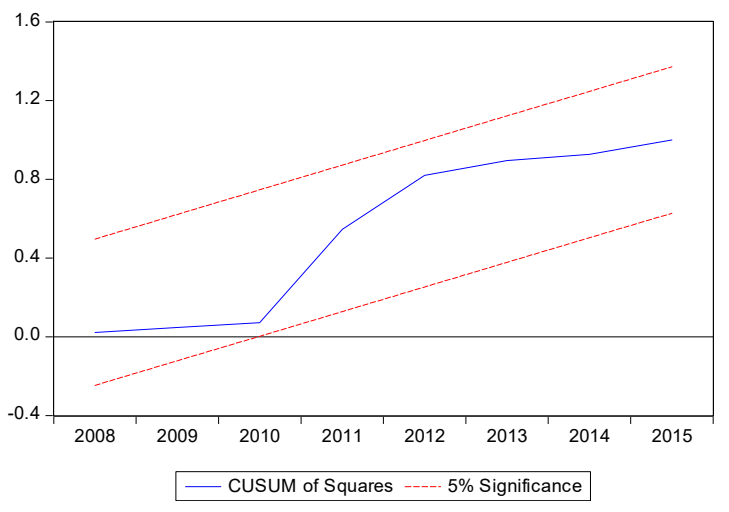

Figure 7. Stability Test (Cusum of Squares)

The long run stability of the parameters is examined by the test of Cumulative Sum and Cumulative Sum of Squares with the use of recursive residuals. Since the statistical plots are located within the critical boundary at the both tests at 5\% level of significance, the hypothesis of "the regression equation is correctly specified" is confirmed. Therefore, it is evident that the parameter is stable. The diagnosis of residual analysis with respect to heteroskedasticity, normality test, and autocorrelation shows that the results are robust.

\section{Conclusion}

The tourism sector is one of the prime earning sources and an opportunity that can be used by Sri Lanka from the contribution of the arrival of tourists to the country. Contemporarily, the policies of the Sri Lankan government are designed focusing on increasing the arrivals of tourists into the country. The opportunities of investments attracted towards the tourism infrastructural facilities will pave the way for the multiplier impact possible for the instrumental economic factors and the supply chain within the economy of Sri Lankan. Regardless of several operations being implemented by the government of Sri Lankan, the competitiveness in the tourism sector with the international touristic destinations is still challengeable. In addition, the quality and the standard in connection with the infrastructural facilities, the services of facilitations, the qualitative products should be improved by Sri Lanka along with the compatibility of tourism competitiveness. Further, the tools of publicity and the utilization of modern marketing should be adopted by Sri Lanka's strategic planning so as to compete with the global tourism industry. The main purpose of this study is to assess the effect of infrastructure on Touristic operations in Sri Lanka. This study used model to achieve the real goal of the research. To achieve its goal, Confidence Ellipse, the nonparametric approach, Nearest Neighbor Fit, and Kernal Fit were used to explore the relationship in this study. Then, Co-integration analysis, Causality Analysis, and Error Correction Model which are the parametric econometric techniques are used to be investigated. The association-ship between on TA the long run relationship indicated that the RK and TR have been positively and statistically significant at $5 \%$ level. The long run relationship between SR and TA has been positively and statistically significant at $1 \%$ level. The Relationship between infrastructure on TA model in short run, the adjustment speed coefficient of error 
correction term is statistically significant and has expected negative sign. According to the results of Granger Causality tests, in the models there are two way causal relationships.

\section{References}

Alegre J., \& Cladera M. (2006). Repeat visitation in mature sun and sand holiday destinations. Journal of Travel Research, 44(3), 288-297. https://doi.org/10.1177/0047287505279005

Alex-Onyeocha, O. U. (2015). The impact of road transportation infrastructure on tourism development in Nigeria. Pearl Journal of Management, Social Science and Humanities, 1(2), 48-55.

Bulbeck, C. (2005). Facing the Wild. Ecotourism, Conservation and Animal Encounters, Earthscan London.

Central Bank of Sri Lanka. (2018). Economics and Social Statistics of Sri Lanka. Colombo: Central Bank of Sri Lanka.

Fareed, R., Zaman Haider, Syed Usman, Naeemud Din, \& Bilal Tariq, M. (2016). The effect of terrorism and infrastructure on tourism industry: A case of Pakistan. International Journal of Research in Economics \& Social Sciences.

Groth, A. (2000). Sustainable tourism and the environment. Connect, 25(1), 1-2.

Gunn, C. A., \& Var, T. (2002). Tourism Planning: Basics, Concepts and Cases (4th ed.). UK: Routledge.

Hultsman, J., Cottrell, R. L., \& Zales-Hultsman, W. (1999). Planning Parks for People. State College, Pennsylvania: Venture Publishing Company.

Ministry of Economic Development. (2011-2016). Tourism Development Strategy. Colombo: Ministry of Economic Development.

Monthly Statistical Bulletins. (2016). Retrieved from http://www.sltda.lk/node/745

Reynolds, T., Charles, K., Jia, L., \& Christin, Z. Q. (2004). Networking for Foreign Direct Investment: The Telecommunications Industry and Its Effect on Investment. Information Economics and Policy, 16, 159-164. https://doi.org/10.1016/j.infoecopol.2003.07.001

Tourism Development Authority. (2018). Annual Report, Sri Lanka Tourism Development Authority, Colombo, Sri Lanka. Retrieved from http://www.sltda.lk/statistics

Yoon, Y., \& Uysal, M., (2005). An examination of the effects of motivation and satisfaction on destination loyalty: A structural model. Tourism Management, 26(1), 45-56. https://doi.org/10.1016/j.tourman.2003.08.016

\section{Copyrights}

Copyright for this article is retained by the author(s), with first publication rights granted to the journal.

This is an open-access article distributed under the terms and conditions of the Creative Commons Attribution license (http://creativecommons.org/licenses/by/4.0/). 